DOI: 10.14451/1.194.92

\title{
СПЕЦИФИКА РИСКОВ ОРГАНИЗАЦИЙ ПРОИЗВОДСТВЕННОЙ ИНФРАСТРУКТУРЫ ГАЗОВОЙ ПРОМЫШЛЕННОСТИ
}

\author{
(C) 2021 Карлик Александр Евсеевич \\ доктор экономических наук, профессор, заведующий кафедрой экономики и управления \\ предприятиями и производственными комплексами \\ Санкт-Петербургский государственный экономический университет, Россия, Санкт-Петербург \\ E-mail: Karlik1@mail.ru
}

\section{() 2021 Митина Юлия Андреевна}

соискатель кафедры экономики и управления предприятиями и производственными комплексами Санкт-Петербургский государственный экономический университет, Россия, Санкт-Петербург

E-mail: yulia.a.mitina@gmail.com

В статье рассматриваются проблемы управления рисками организаций производственной инфраструктуры газовой промышленности. Приведен сравнительный анализ основных рисков, присущих российским и зарубежным организациям инфраструктуры газовой промышленности. Приведены данные по износу отдельных элементов газотранспортной системы, определяющие уровень рисков.

Ключевые слова: газовая промышленность; управление рисками; система управления производственными рисками; организации инфраструктуры

Современные роль и место энергетики в мировом воспроизводстве позволяют говорить о нарастающих рисках в рамках энергетических систем, практически, во всех отраслях энергетики и, в первую очередь, сетевых структурах, тем более, что последние занимают доминирующее место в процессе передачи ряда энергоносителей (нефть, газ) и частично результатов их использования в электроэнергетике. Усложнение энергетических систем, весьма значимые последствия техногенных инцидентов в этих системах, непосредственно влияющих на возможности реализации жизнедеятельности - все это предполагает необходимость выявления и оценки соответствующих рисков, а также ранжирования их с целью осуществления превентивных действий по минимизации последствий реализации рисков. Соответственно, исследование вопросов управления рисками производственной инфраструктуры газовой промышленности является важным аспектом развития теоретических и практических основ повышения эффективности самих организаций инфраструктуры и всего топливно-энергетического комплекса, равно как и экономики страны в целом.

Нужно отметить, что в последние годы, хотя и идет определенное обновление производственного аппарата газовой промышленности, тем не менее уже критичным становится старение основных средств, что влечет за собой непропорциональный рост затрат на обслуживание и восстановление или замену для предупреждения ситуаций, генерирующих соответствующие риски.

Как известно, газовая промышленности включает в себя широкий спектр видов деятельности: геологоразведка, добыча, транспортировка, переработка, хранение и реализация, однако основной организационной особенностью ее является наличие группы организаций производственной инфраструктуры (магистральные газопроводы, газораспределительные сети) и наличие высоких производственных рисков, связанных с необходимостью обеспечения безопасного и бесперебойного обеспечения внутренних и зарубежных конечных потребителей. Авторами, для определения и идентификции основных рисков организаций инфраструктуры газовой промышленности был проведен сравнительный анализ крупнейших российских и зарубежных предприятий производственной инфраструктуры газовой промышленности, к которым в России можно отнести *:

- ПАО «Газпром» - в части газотранспортных предприятий (www.gazprom.ru) [1];

- ПАО «Транснефть», осуществляющее

* Выборка произведена на основе рейтинга РБК ТОП 500 компаний России» (www.rbc.ru) 
транспортировку нефти и нефтепродуктов по системе магистральных газопроводов (www. transneft.ru) [2].

Среди зарубежных организаций инфраструктуры были выбраны такие организации как *:

- National grid (Великобритания и США), осуществляющее передачу электроэнергии по магистральным сетям, а также транспортировку газа по магистральным и распределительным трубопроводам (http://www2.nationalgrid.com) [3];

- E.On (Германия), осуществляющее передачу электроэнергии и транспортировку газа по распределительным сетям и газопроводам (https://www.eon.com) [4].
Основные риски, имманентные приведенным выше организациям инфраструктуры и отраженные в том числе на Интернет-страницах указанных компаний и в годовых отчетах за 2019 год, приведены в таблице 1. Наименования основных рисков приведены в соответствии с корпоративными документами исследуемых организаций.

Приведенные данные свидетельствуют о том, что рассматриваемые зарубежные организации, система управления рисками которых давно прошла этап становления в отличии от российских компаний, выделяют среди своих рисков -производственные риски (операционнотехнологические; риски отказов и т.п.).

* Выборка произведена на основе имеющихся материалов авторов

Таблица 1. Основные риски, присущие исследуемым организациям инфраструктуры, выделенные непосредственно компаниями

\begin{tabular}{|c|c|c|c|}
\hline ПАО «Газпром» & ПАО «Транснефть» & E.On & National grid \\
\hline \multirow{9}{*}{$\begin{array}{l}\text { Информация об основ- } \\
\text { ных рисках, специфич- } \\
\text { ных для производствен- } \\
\text { ной инфраструктуры, не } \\
\text { публикуется в открытых } \\
\text { источниках. }\end{array}$} & $\begin{array}{l}\text { Валютные и процентные } \\
\text { риски }\end{array}$ & $\begin{array}{l}\text { Риски, связанные с госу- } \\
\text { дарственным регулирова- } \\
\text { нием (высокий) }\end{array}$ & $\begin{array}{l}\text { Риски, связанные с ро- } \\
\text { стом бизнеса }\end{array}$ \\
\hline & $\begin{array}{l}\text { Государственное регу- } \\
\text { лирование тарифов на } \\
\text { транспортировку нефти / } \\
\text { нефтепродуктов }\end{array}$ & $\begin{array}{l}\text { Операционно- } \\
\text { технологические риски } \\
\text { (средний) }\end{array}$ & $\begin{array}{l}\text { Риски, связанные с госу- } \\
\text { дарственным регулиро- } \\
\text { ванием }\end{array}$ \\
\hline & Фискальные риски & $\begin{array}{l}\text { Риски, связанные со здо- } \\
\text { ровьем, безопасностью и } \\
\text { экологией (низкий) }\end{array}$ & $\begin{array}{l}\text { Риски, связанные с } \\
\text { развивающимися техно- } \\
\text { логиями }\end{array}$ \\
\hline & $\begin{array}{l}\text { Невыполнение планов по } \\
\text { загрузке новых маги- } \\
\text { стральных нефтепрово- } \\
\text { дов }\end{array}$ & $\begin{array}{l}\text { Маркетинговые риски } \\
\text { (высокий) }\end{array}$ & $\begin{array}{l}\text { Риски отказов произ- } \\
\text { водственных основных } \\
\text { средств, влияющие на } \\
\text { безопасность }\end{array}$ \\
\hline & $\begin{array}{l}\text { Влияние изменения } \\
\text { политики государства в } \\
\text { части налогообложения } \\
\text { нефтяной отрасли на } \\
\text { грузооборот }\end{array}$ & $\begin{array}{l}\text { Стратегические риски } \\
\text { (средний) }\end{array}$ & $\begin{array}{l}\text { Риски, связанные с } \\
\text { управлением и обработ- } \\
\text { кой данных }\end{array}$ \\
\hline & $\begin{array}{l}\text { Акт незаконного вме- } \\
\text { шательства, в том числе } \\
\text { террористический акт } \\
\text { или покушение на его } \\
\text { совершение }\end{array}$ & $\begin{array}{l}\text { Финансовые риски (уме- } \\
\text { ренный) }\end{array}$ & $\begin{array}{l}\text { Риски, связанные с ки- } \\
\text { бернарушениями }\end{array}$ \\
\hline & $\begin{array}{l}\text { Отключение внешнего } \\
\text { электроснабжения объек- } \\
\text { тов ПАО «Транснефть» }\end{array}$ & & $\begin{array}{l}\text { Риски, связанные с доста- } \\
\text { точностью компетенций } \\
\text { у руководства для реали- } \\
\text { зации стратегии }\end{array}$ \\
\hline & $\begin{array}{l}\text { Риск изменения зако- } \\
\text { нодательных и иных } \\
\text { нормативно-правовых } \\
\text { актов, устанавливающих } \\
\text { и регулирующих техни- } \\
\text { ческие требования и ус- } \\
\text { ловия производственной } \\
\text { деятельности Компании }\end{array}$ & & \\
\hline & $\begin{array}{l}\text { Риск отзыва лицензии } \\
\text { банка-контрагента }\end{array}$ & & \\
\hline
\end{tabular}


Поддержание и развитие инфраструктуры является важным условием роста экономики, так как данные отрасли не только лимитируют расширенное воспроизводство, но и создают угрозу структурных, техногенных и иных кризисов [7], являясь таким образом высоко рискованными. Отнесение же производственных рисков к числу наиболее значимых специфично для организаций инфраструктуры и обусловлено тем, что данные организации являются капиталоемкими, а их основные производственные процессы сосредоточены на эксплуатации производственных основных средств в целях обеспечения бесперебойного газо- или электроснабжения в отличие от других организаций газовой промышленности, например, осуществляющих реализацию газа на экспорт или внутренним потребителям, для которых на первый план выходят рыночные, политические или риски государственного регулирования. Как следствие, в организациях инфраструктуры отмечается высокая доля текущих затрат на обслуживание и восстановление основных средств.

При этом российская специфика производственной инфраструктуры газовой промышленности, на примере которой проводится данное исследование, заключается в общем «старении» основных средств. Как известно, основная часть газотранспортной системы России была построена в 70-80-е годы прошлого века. К настоящему времени износ основных фондов по линейной части магистральных газопроводов составляет более половины - $56 \%$ в соответствии с данными Росстата.

Данные таблицы 2 демонстрируют, что по итогам 2019 года срок эксплуатации почти 57\% магистральных газопроводов, эксплуатируемых ПАО «Газпром» на территории России, составляет более 31 года.

Все это несомненно ведет к росту роли про- изводственных рисков, поскольку влияние отказов и аварий на производственных объектах нельзя недооценивать.

В соответствии с данными Ростехнадзора в 2019 году на опасных производственных объектах магистрального трубопроводного транспорта произошло 12 аварий. В сравнении с 2018 годом (6 аварий) на объектах магистрального трубопроводного транспорта количество аварий увеличилось в 2 раза [5].

Поддержание и развитие инфраструктуры является важным условием роста экономики, так как данные отрасли не только лимитируют расширенное воспроизводство, но и создают угрозу структурных, техногенных и иных кризисов, являясь таким образом высоко рискованными.

Таким образом, отличительные черты организаций инфраструктуры газовой промышленности, определяющие доминирующую роль производственных рисков, являются следующими:

1) Высокая капиталоемкость, определяемая преобладающими затратами на создание основных средств;

2) сосредоточение основных производственных процессов на эксплуатации основных средств, и как следствие, высокая доля текущих затрат на обслуживание и восстановление основных средств;

3) тенденция общего «старения» основных средств и повышение роли производственных рисков, заключающихся в отказах и авариях на объектах инфраструктуры, создающих угрозу структурных, техногенных и иных кризисов;

4) влияние реализации рисковых ситуаций на бесперебойное снабжение потребителей, что в свою очередь может ограничить возможности расширенного воспроизводства и рост экономики страны в целом.

Таблица 2. Распределение протяженности магистральных газопроводов газотранспортных обществ Группы Газпром на территории России по срокам эксплуатации по состоянию на 31.12.2019 г.

\begin{tabular}{|l|c|c|}
\hline \multicolumn{1}{|c|}{ Срок эксплуатации } & Протяженность, тыс. км & Доля, \% \\
\hline До 10 лет (включительно) & 17,3 & 9,5 \\
\hline От 11 до 20 лет (включительно) & 16,2 & 23,8 \\
\hline От 21 до 30 лет (включительно) & 40,9 & 32 \\
\hline От 31 до 40 лет (включительно) & 55,2 & 14,4 \\
\hline От 41 до 50 лет (включительно) & 24,8 & 10,3 \\
\hline Свыше 50 лет & 17,7 & 100 \\
\hline ВСЕГО & 172,1 & \\
\hline
\end{tabular}




\section{Библиографический список}

1. Официальный сайт компании National Grid - URL: http://www2.nationalgrid.com

2. Официальный сайт компании E. On - URL: https://www.eon.com

3. Официальный сайт компании ПАО «Газпром» - URL: www.gazprom.ru

4. Официальный сайт компании ПАО «Транснефть» - URL: www.transneft.ru

5. Официальный сайт Федеральной службы по экологическому, технологическому и атомному контролю (Ростехнадзор) - URL: http://www.gosnadzor.ru/public/annual_reports

6. Официальный сайт Федеральной службы государственной статистики (Росстат) - URL: http://www.rosstat. gov.ru

7. Бернстайн П.Л. Против богов: Укрощение риска.- Литрес, 2017.-240 с. 